\title{
Lessons of Fresh Start can guide schools seeking to boost student fruit consumption
}

by Patricia B. Crawford, Gail Woodward-Lopez, Wendi Gosliner and Karen L. Webb

Less than $11 \%$ of young school-aged children eat the recommended amounts of fruits and vegetables, despite abundant evidence that these foods protect against many types of cancer, heart disease and diabetes, and when combined with other dietary changes can help protect against obesity. In 2005, California became the first state to address the availability of fresh and local produce in the federal School Breakfast Program through state funding. The California Fresh Start Program doubled the number of different fresh fruits offered to students. With the greater variety, the number of fresh fruit servings taken by students in the Fresh Start pilot program more than doubled. Evaluation of the program revealed many lessons, which are especially important now, as schools across the country prepare to increase the number of fruits and vegetables offered in the School Breakfast Program by or before July 2014 as mandated by the Healthy, Hunger-Free Kids Act.

While the health benefits of fruits and vegetables are widely acknowledged, consumption of these foods among children and youth is at a low level. Fewer than $11 \%$ of school-aged children eat fruits and vegetables at the recommended levels (Guenther et al. 2006); as many as one-third of high school students eat vegetables less than once a day, and $28 \%$ eat fruit less than once a day (CDC 2011). Further, data collected by the Centers for Disease Control and Prevention's National Health and Nutrition Examination Survey shows that the fruits and vegetables adolescents consume tend to be the less nutritious forms: Fruit juices and fried potatoes are major contributors (Kimmons et al. 2009). Children's low

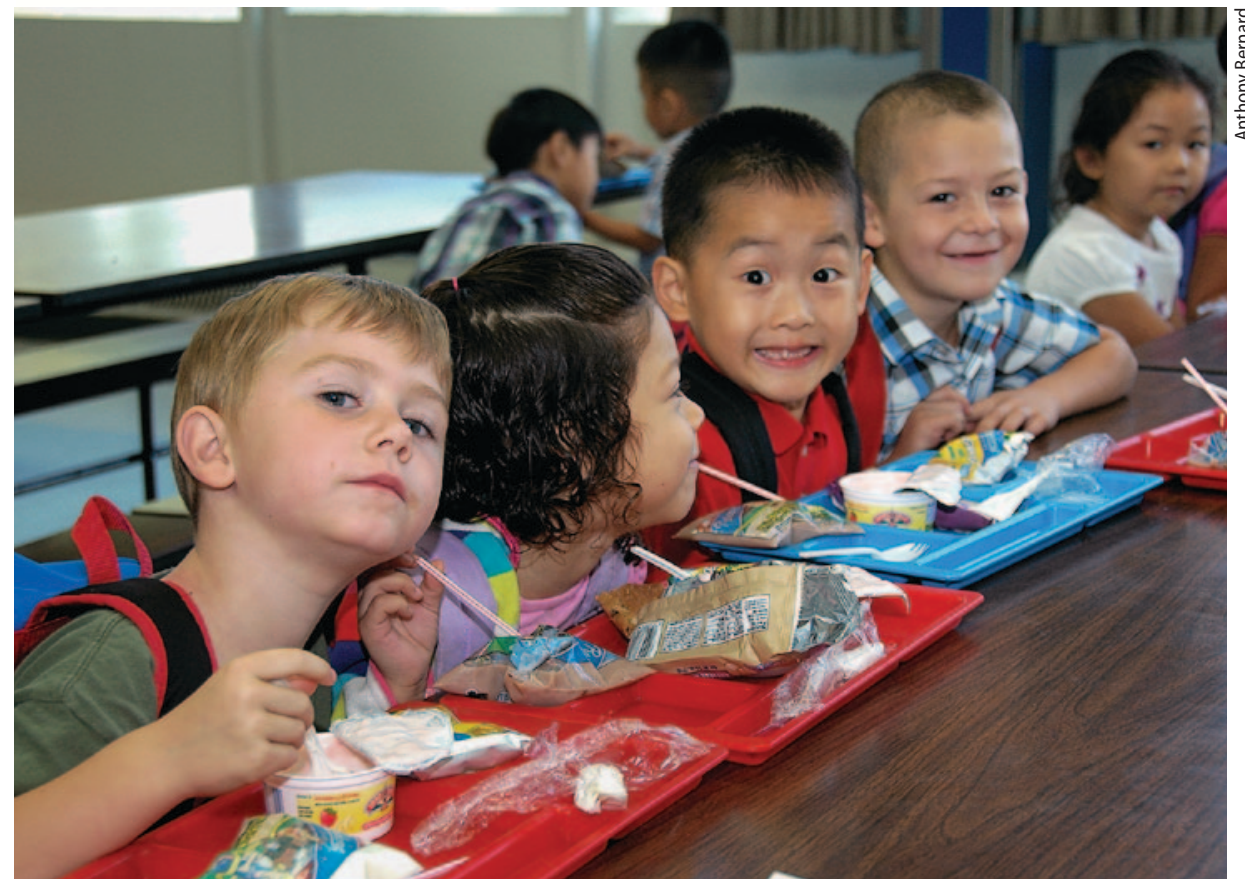

Children consume up to half of their daily calories at school, which gives schools a potentially critical role in increasing children's consumption of fresh fruits and vegetables. Above, children eat breakfast at Centennial Elementary School, Fresno Unified School District.

consumption of fruits and vegetables has been documented in numerous studies. It is clearly addressed in the 2010 USDA Dietary Guidelines (USDA DHHS 2010), which note that intakes of fried potatoes and fruit beverages have seen recent growth, while intakes of fresh fruits and vegetables have not.

\section{Importance of school programs}

The United States is confronting an epidemic of poor nutrition among children. Schools can play an important role in addressing this epidemic, both by serving food directly to students and by using the power of role modeling to demonstrate healthy diets to students and their families.

Despite educational efforts, at the population level fruit and vegetable intakes have changed very little, prompting some to suggest that alternative individual-, community- and population-level interventions are necessary (Thomson and Ravia 2011). One promising approach is to provide more servings of fruits and vegetables in schools and youth-serving programs (Delgado-Noguera et al. 2011;
Knai et al. 2006). Findings suggest that if children are provided with healthful, appealing foods, they will eat them.

A European review of the literature found that availability and accessibility of fruits and vegetables and taste preferences were the determinants most consistently and positively related to consumption (Blanchette and Brug 2005). Furthermore, a combination of increased access to fruits and vegetables at school with nutrition education in the curriculum has a considerably greater impact than nutrition education alone, although both are important (Coyle et al. 2009; He et al. 2009; Knai et al. 2006). The USDA Fresh Fruit and Vegetable Program, which provides an extra serving of a fruit or vegetable as a between-meal snack to children at schools in low-income communities that apply for the program, is being evaluated and shows promise for increasing children's consumption (FNS 2010).

Online: http://californiaagriculture.ucanr.edu/ landingpage.cfm?article=ca.v067n01p21\&fulltext=yes DOI: 10.3733/ca.v067n01p21 
The greatest room for improvement in children's fruit and vegetable consumption is at school, where children consume up to half of their calories (Briefel et al. 2009). The National Academy of Sciences Institute of Medicine has urged school action to increase fruit and vegetable intake (Glickman et al. 2012), and federal policies resulting from the Healthy, Hunger-Free Kids Act of 2010 mandate this increase. during the 2006-2007 school year, and recommend promising strategies for increasing produce consumption by children in the school setting. The barriers we identify to program implementation can provide guidance to policymakers and administrators in school districts nationwide. A comprehensive report on the California Fresh Start Program can be found at the Center for Weight and

\section{Students eating the school breakfast took more than twice as many fresh fruit servings during the California Fresh Start Program than before the program.}

\section{The California Fresh Start Program} was a pilot school breakfast program that informed state and federal policymakers about the opportunities, challenges and benefits of programs to increase produce consumption in schools. Lessons from the program are especially important now for two reasons: School districts will be increasing offerings of fruits and vegetables in the School Breakfast Program in July 2014 to meet the new school nutrition guidelines in the Healthy, Hunger-Free Kids Act; and childhood obesity has escalated, with the consequent risk of serious chronic conditions including type 2 diabetes and heart disease. Here, we highlight the results of the California Fresh Start Program, which was conducted
Health, UC Berkeley, website: http://cwh. berkeley.edu/sites/default/files/primary_ pdfs/Evaluation_of_the_California_ Fresh_Start_Program_Report.pdf.

\section{California legislation}

Responding to the critical state of children's nutritional health, California enacted Senate Bill 281, commonly known as the California Fresh Start Program (CFSP), which was signed into law in 2005. It was the first statewide legislation to specifically address fresh and local produce in schools.

The innovative pilot program offered a 10-cent per meal reimbursement to schools to increase the servings of fruits and vegetables they offered in

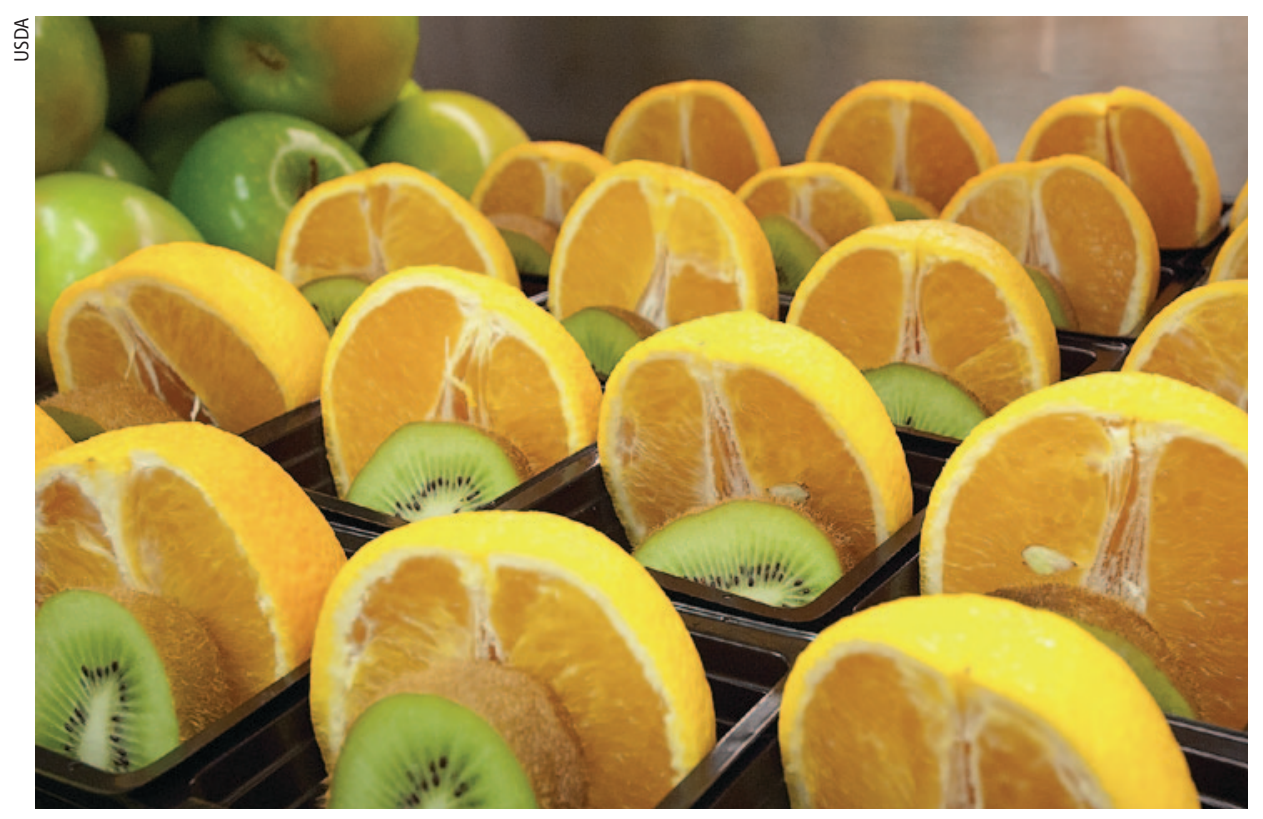

To meet the nutrition guidelines in the Healthy, Hunger-Free Kids Act, schools need to increase servings of fruits and vegetables. Above, fresh oranges and kiwifruit are attractively combined to appeal to high school students.

the School Breakfast Program. Priority was given to serving fresh fruits and vegetables and, where possible, California-grown produce.

The program goals were to promote the consumption of fresh fruits and vegetables, increase school breakfast participation and ultimately improve children's lifelong eating habits and decrease the incidence of obesity. Supplementing fruits and vegetables in the breakfast program, which serves more than a million California students each day, was an important first step in reaching school-age children, nearly all of whom are at nutritional risk due to low produce consumption.

\section{Program participation}

Of California public school students who eat breakfast at school, $78 \%$ were reached by the California Fresh Start Program during the 2006-2007 school year. Fewer than half of California's school districts participated in the program, but participating school districts had larger student enrollments than nonparticipating districts (median enrollment was 4,069 and 1,047, respectively).

A higher proportion of participating versus nonparticipating districts were in urban areas. The ethnic profile of students (mostly white and Hispanic) and the average school breakfast participation rates (about 20\%) were similar in participating and nonparticipating school districts.

\section{Program evaluation}

An independent evaluation of the California Fresh Start Program was conducted to answer the following questions:

- How did schools spend the additional 10 cents per breakfast?

- To what extent did school purchases of fresh fruits and vegetables increase?

- What impact did the program have on children's dietary intake of fruits and vegetables and on their participation in the School Breakfast Program?

- What effects did the program have on school food service operations, including needs for equipment and facilities, labor, nutrition education materials and staff training on safe handling, serving and marketing of fruits and vegetables?

School districts were stratified according to their number of elementary, middle 
and high schools, and the schools were randomly selected for participation in the evaluation. Of 93 schools that were contacted, 20 were ineligible because they were not participating in the program and four declined to participate in the evaluation. Of the remaining 69 schools, 61 were able to supply sufficiently complete data for the evaluation. The Committee for the Protection of Human Subjects at UC Berkeley approved the study. Parents received letters about the study, and students consented verbally to participate.

Data were collected before and during the program. Breakfast menu production records and invoices were sought from the schools' child nutrition directors on 20 randomly selected days during the months of September, October and November in the year before the program was implemented and during the program (2006 and 2007). Data from the menu production records included the nature and number of fruit servings prepared and taken by students at breakfast. Nonfood expenses directly relating to operating the program were also reported.

Of the 61 nutrition directors, 55 recorded their views of the program's impact on nutrition services operations, perceived student satisfaction, challenges and barriers to operating the program, nutrition education and promotional techniques, and staff training and needs. A stratified random sample of 18 schools was selected for site visits, which were successfully conducted at 16 schools: six elementary, six middle and four high schools. This sample was similar to other schools participating in the program in terms of school level, enrollment, geographic location, free- and reducedprice enrollment and student ethnicity.
Interviews with nutrition directors were conducted at each of the 16 schools.

Student surveys were completed by 1,205 students in grades 4 to 12 in a convenience sample of one or two classes at each of the 16 visited schools (total of 28 classes) as well as at the school cafeterias during breakfast service. Questions were asked about where breakfast is eaten, how often fruits and vegetables are consumed at breakfast, favorite fruits to eat at breakfast, importance of eating fruits and vegetables at breakfast, change in fruit and vegetable consumption compared to the previous year and basic sociodemographic information. The cafeteria questionnaire asked additional questions regarding opinions about the school breakfast and perceptions of change since the previous year. The classroom questionnaire included questions regarding barriers to eating the school breakfast.

In addition, trained research staff facilitated classroom discussions with students in 28 classes in grades 4 to 12 (a convenience sample of one or two classes at each of the 16 schools). Students were questioned about their views on breakfast in general, the School Breakfast Program, the California Fresh Start Program and factors influencing their school breakfast participation and food choices.

Nutrition directors recorded School Breakfast Program participation on a standardized form. The researchers obtained monthly participation data during the course of the evaluation, including number of operating days and school average daily attendance. In addition, observations of the breakfast environment were made at each of the visited schools.

Costs of specific fruits and vegetables were calculated from invoices provided

TABLE 1. Number of different fruits, by form, offered per day at breakfast before and during the California Fresh Start Program ( $n=61$ schools)

\begin{tabular}{|c|c|c|c|}
\hline Fruit & Before program & During program & Increase (decrease)* \\
\hline & $\ldots \ldots \ldots \ldots \ldots \ldots$ & .... & $\%$ \\
\hline Fresh & 0.66 & 1.38 & $110+$ \\
\hline Juice & 0.75 & 0.73 & (2) \\
\hline Canned/frozen & 0.30 & 0.37 & 25 \\
\hline Dried & 0.05 & 0.07 & 42 \\
\hline Total (all forms) & 1.75 & 2.55 & $46 t$ \\
\hline
\end{tabular}

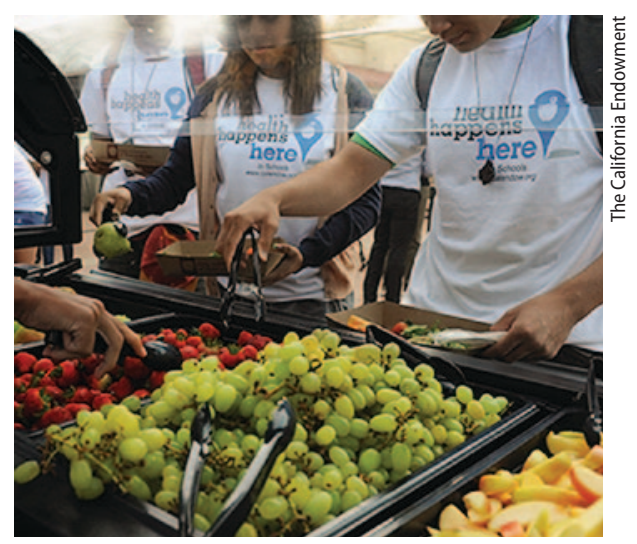

Student surveys revealed a preference for fruit to be served in salad bar style. Above, a Sacramento school offers fruit alongside vegetables in its salad bar.

by the nutrition directors. The costs of fruits and vegetables prepared and served were based on the total value of the prepared items reported on the menu production records. Nonfood expenses identified on invoices were classified as transportation, facilities, large and small equipment, material, promotional, training, additional staff time, and other. The percentage of total nonfood expenses for each category was calculated.

Differences in both fresh fruit and total fruit taken by students and in the variety of fruits offered at each school were calculated from menu production records and analyzed by $t$-test. Descriptive findings were reported for schools demonstrating more successful program implementation, specifically, schools with increases of 0.10 or more units of total and fresh fruit taken and increases greater than 0.90 for number of different fresh fruits offered.

Although the California Fresh Start Program was designed to increase fruit and vegetable consumption, its effect was almost completely seen on fruit consumption, since vegetables were rarely included in the breakfast menu; vegetables represented less than $1 \%$ of produce offered to students. Thus the results presented here are based on fruit offerings.

\section{Increased fruit consumption}

The California Fresh Start Program resulted in substantial increases in the variety of all, and especially fresh, fruits offered to students. More than twice as many different fresh fruits were offered per day during the program compared with the same period a year before: an average of 1.38 fruits compared to 0.66 (table 1). When considering all forms 
of fruit (fresh, juice, canned, frozen and dried), there was a $46 \%$ increase in the average number of fruits offered per day: 2.55 fruits compared with 1.75 prior to the program (table 1). The California Fresh Start Program brought the offerings into compliance with dietary recommendations for two produce servings at breakfast.

During the program, fresh fruit made up the majority of the fruit offered at breakfast. Juice, which previously had been the primary source of fruit, decreased substantially as a proportion of total fruit. All types of fresh fruit were offered with greater frequency; however, apples remained the most commonly offered individual fruit, followed by oranges and bananas. Stone fruits, though offered less frequently, showed the greatest percentage increase during the program (table 2).

Our findings suggest that when offered a greater variety of fruits and less juice, students will increase their intake of fruit, especially fresh varieties (fig. 1). Students eating the school breakfast took more than twice as many fresh fruit servings during the California Fresh Start Program than before the program, 0.32

TABLE 2. Frequency (\% of observation days) with which different fresh fruits were offered at school breakfast before and during the California Fresh Start Program ( $n=61$ schools)

\begin{tabular}{|c|c|c|c|}
\hline Fruits & $\begin{array}{l}\text { Before } \\
\text { program } \\
\text { mean }\end{array}$ & $\begin{array}{c}\text { During } \\
\text { program } \\
\text { mean }\end{array}$ & Increase ${ }^{*}$ \\
\hline Apples & 16 & 37 & $130 t$ \\
\hline Oranges & 9 & 25 & $170+$ \\
\hline $\begin{array}{l}\text { Assorted } \\
\text { fresh fruit }\end{array}$ & 17 & 24 & 39 \\
\hline Bananas & 10 & 19 & $84 \neq$ \\
\hline Stone fruits & 2 & 5 & $221 \neq$ \\
\hline Grapes & 2 & 5 & 98 \\
\hline $\begin{array}{l}\text { Strawberries/ } \\
\text { blueberries }\end{array}$ & 2 & 3 & 43 \\
\hline Melons (all) & 2 & 3 & 38 \\
\hline Kiwi & $<1$ & 2 & $-\S$ \\
\hline Pineapple & 0 & $<1$ & - \\
\hline $\begin{array}{l}\text { Tangerines/ } \\
\text { tangelos }\end{array}$ & $<1$ & 2 & - \\
\hline Pears & $<1$ & 2 & - \\
\hline
\end{tabular}

* Percentages were rounded to the nearest whole number.

† Significant at $P<0.01$, using paired $t$-tests.

₹ Significant at $P<0.05$, using paired $t$-tests.

$\S$ Percentages were too small for meaningful estimates. servings compared to 0.14 , while taking substantially less juice and nearly the same amounts of canned, frozen and dried fruit offerings (fig. 1).

Although there were no direct measures of student consumption in this evaluation, the amounts taken, as recorded by food service personnel, provide a reasonable indirect basis for assessing student consumption. Observations by research staff and food service personnel confirmed that most students who choose to take a fruit at breakfast do eat

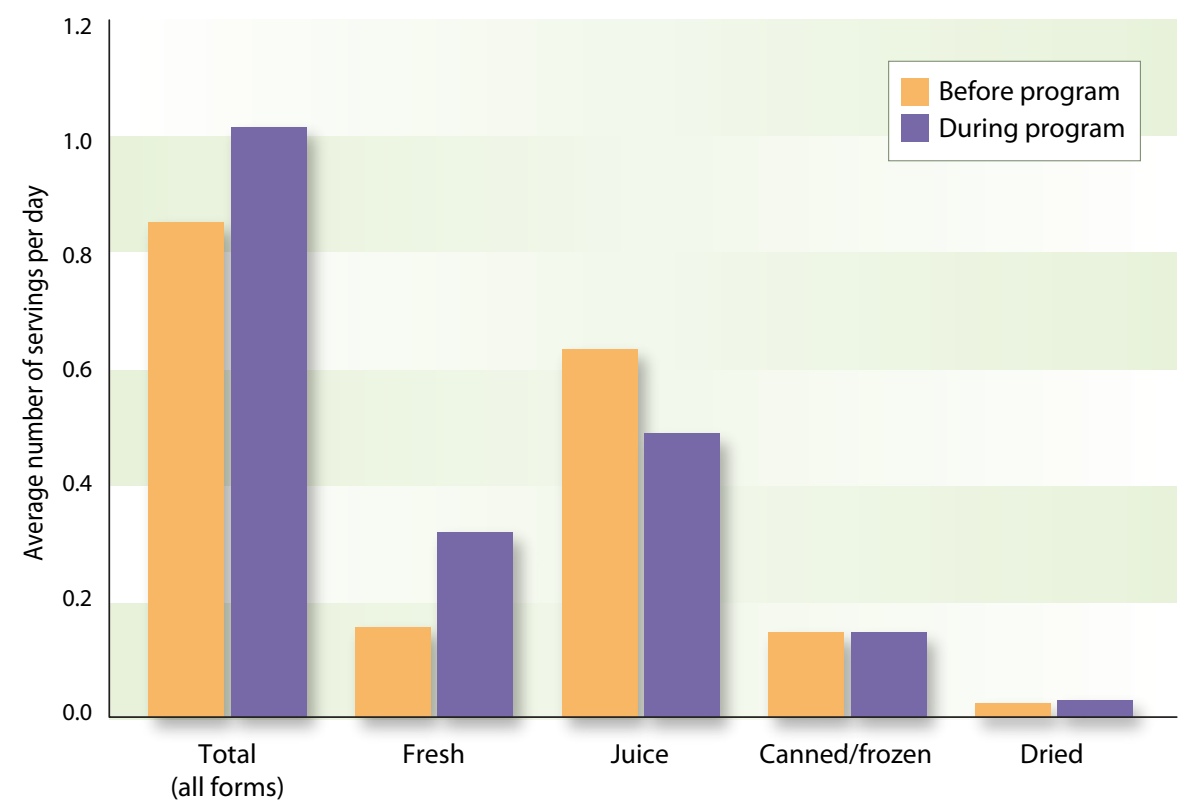

Fig. 1. Average number of servings of fruits taken by students per day at breakfast before and during the California Fresh Start Program ( $n=44$ schools).

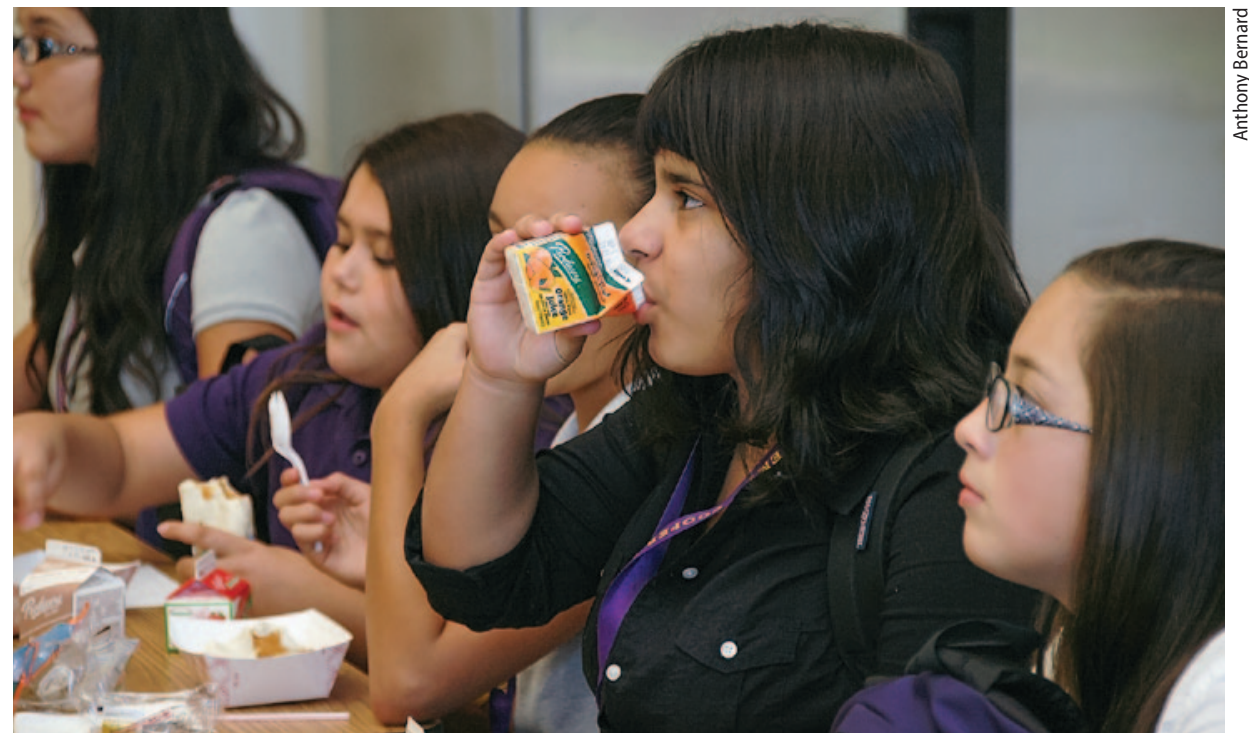

During the California Fresh Start Program, students eating school breakfast took more than twice as many fresh fruit servings as before the program. Juice, the largest source of fruit, decreased substantially as a proportion of total fruit offered. Above, Fresno students at Cooper Academy enjoy breakfast. it. Therefore, student consumption of fresh fruit at breakfast appears to have doubled as a result of the California Fresh Start Program.

During the program, students took more of almost all types of fruit; however, the percentage increases were greatest for less common fruits such as cantaloupe, tangerines/tangelos and blueberries, which were not often offered before the program. Increases of about $20 \%$ to $30 \%$ were observed for common fruits such as apples, bananas and oranges; increases 
were $100 \%$ or more for tangerines, berries and cantaloupe, reflecting their appeal among students, and the low frequency with which they were offered before the program. Although the greatest increase in offerings occurred for the most common fruits - apples, oranges and bananas - the relative increase in servings of fruits was highest for the less common fruits. The demand for more common fruits may be approaching saturation, but unmet demand exists for a wider variety of fruits. Thus, future increases in the fruit servings students take at breakfast will likely require offerings of fruits other than apples, oranges and bananas.

\section{Schools with greatest success}

While the overall impact of the program on the amount of fruit - particularly the amount of fresh fruit — taken by students is impressive, this impact is even more dramatic when looking specifically at the schools that experienced the greatest success in implementing the program. At these schools, the California Fresh Start Program led to a $46 \%$ increase in the total amount of fruits taken by students, and a $383 \%$ increase in the fresh fruits and vegetables taken (table 3). It had the most impact in schools where students took the lowest number of fruit servings before the program - schools with the greatest need for an increase in produce intake. Schools that offered increased quantities of fruit, more variety of fruits and more unusual fruits and less juice were most successful in increasing student selection of fresh fruit. Limiting juice and providing fruits other than apples, oranges and bananas appear to be particularly important for increasing student consumption of fresh fruit. The fruits most often served at breakfast are rarely the ones that students most prefer (e.g., watermelon and strawberries).

\section{Students' attitudes}

Students' attitudes toward eating fruit, already positive, showed modest changes during the program. Most students (77\%) reported it was important to have fruit at breakfast, saying that fruits and vegetables are "good for you because it's healthy, makes you strong; there is natural sugar, and it contains vitamins like A and C." However, only $13 \%$ said they always eat fruits and vegetables at breakfast, and only $19 \%$ said they often do. This may
TABLE 3. Number of total and fresh fruits taken per student, and variety offered, before and during the California Fresh Start Program, for more- and less-successful schools*

\begin{tabular}{|c|c|c|c|c|c|c|}
\hline \multirow[b]{2}{*}{ Outcome variable } & \multicolumn{3}{|c|}{$\begin{array}{l}\text { More-successful schools } \\
\qquad(n=22)\end{array}$} & \multicolumn{3}{|c|}{$\begin{array}{l}\text { Less-successful schools } \\
\qquad(n=22)\end{array}$} \\
\hline & $\begin{array}{l}\text { Before } \\
\text { program }\end{array}$ & $\begin{array}{l}\text { During } \\
\text { program }\end{array}$ & $\begin{array}{c}\text { Increase } \\
\text { (decrease) }\end{array}$ & $\begin{array}{l}\text { Before } \\
\text { program }\end{array}$ & $\begin{array}{l}\text { During } \\
\text { program }\end{array}$ & $\begin{array}{l}\text { Increase } \\
\text { (decrease) }\end{array}$ \\
\hline & $\cdots \cdots \cdots m$ & $n+\ldots \ldots \ldots$ & $\%$ & $\cdots \cdots \cdots m$ & $n \ldots \ldots \ldots$ & $\%$ \\
\hline Total fruits taken & 0.82 & 1.20 & 46.1 & 0.91 & 0.84 & $(7.7)$ \\
\hline Fresh fruits taken & 0.08 & 0.40 & 383.0 & 0.30 & 0.27 & (11.4) \\
\hline No. of different fruits offered & 1.42 & 3.13 & 120.0 & 2.22 & 2.34 & 5.6 \\
\hline $\begin{array}{l}\text { * More-successful schools were those } \\
\text { below all three cutoffs: } \\
\text { - Change in the mean number of to } \\
\text { - Change in the mean number of fre } \\
\text { - Change in the variety of fruits and }\end{array}$ & $\begin{array}{l}\text { king above the } \\
\text { servings taken } \\
\text { servings taken } \\
\text { getables offere }\end{array}$ & $\begin{array}{l}\text { itoffs in all thre } \\
\text { r student per } \\
\text { students per } \\
\text { ser day (cutoff }\end{array}$ & $\begin{array}{l}\text { of the following } \\
\text { (cutoff }>0.10 \text { ) } \\
\text { ay (cutoff }>0.10 \text { ) } \\
0.90)\end{array}$ & teria; less-succ & ful schools we & those ranking \\
\hline
\end{tabular}

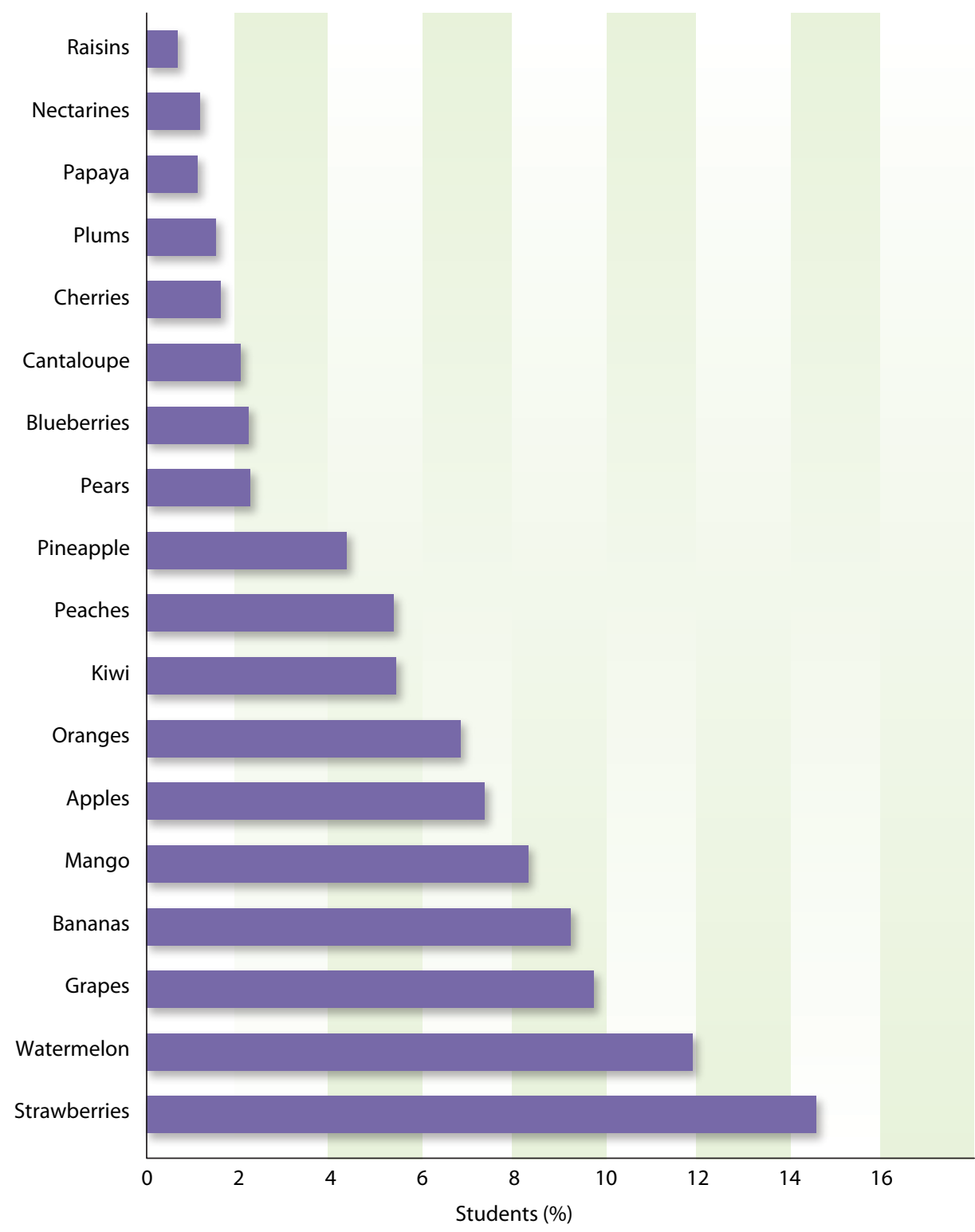

Fig. 2. Student survey responses regarding which one fruit was their favorite $(n=1,205$ students surveyed). 


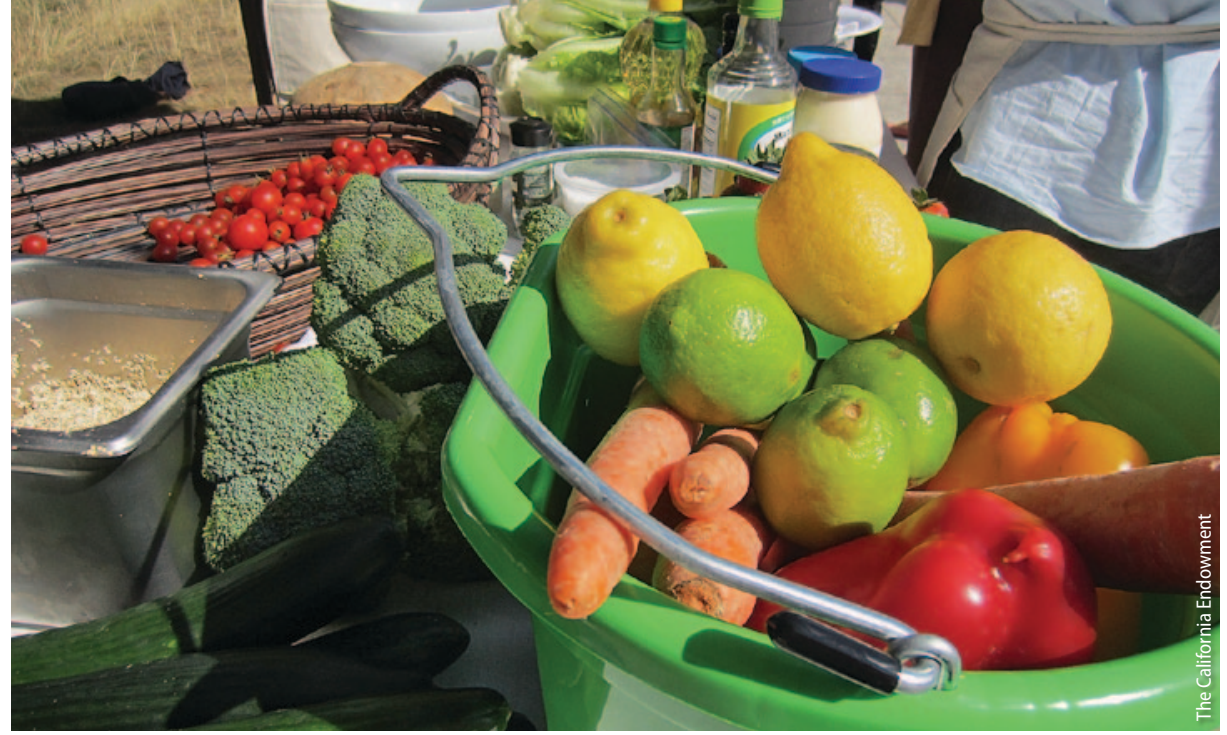

A test kitchen for healthier school meals prepared a variety of vegetables, fruits and homemade vinaigrette to tempt students to try more fresh produce. Variety, convenience, quality and freshness are key concerns among students.

be due in part to the fruits most often served at breakfast not being the fruits students prefer.

Students prefer more exotic fruits than they are currently served. Fruits mentioned were mangos, kiwi, strawberries, peaches, pineapple, watermelon and grapes, with melons and berries being most popular (fig. 2). Students also want more variety in the ways fruit is presented, including chopped fruit, fruit salads, salad-type fruit bars, fruit with condiments and ethnic favorites. Variety, convenience, quality and freshness are key concerns. High school students, in particular, expressed a desire for more tropical fruits such as mangos.

\section{Factors associated with success}

Successful implementation of the California Fresh Start Program was not significantly related to school characteristics or student socio-demographics. The type of school (elementary, middle or high), ethnicity/race of the students, ruralurban geographic location, percentage of free- and reduced-price meal participation and size of student enrollment did not have any statistically significant association with the program's success in terms of the number of fresh and total fruit servings students took or the variety of fruits offered.

Whether students were offered and/ or took more fruit was affected by a variety of school institutional and economic factors, including the physical layout of the school's food service department and the availability of funding for program support. Because the California Fresh Start Program did not mandate or provide funding for facility improvements, it is not surprising that only about $9 \%$ of the schools made improvements to their kitchen, dining area, serving areas or tion indicated that adequate dining space for students was related to students taking more fruit and an appealing dining ambience was related to students taking more fresh fruit.

Almost one-third (31\%) of schools did not have sufficient facilities to seat all students comfortably. The temperature was uncomfortably cold in many of the serving and dining areas, which may have played a role on cold days in students' preference for hot breakfast items rather than cold fruit. The student survey revealed that a majority of students want more options regarding when and where they can eat breakfast, particularly the options of eating in the classroom and indoors or outdoors. Only about one-third of schools offered students the choice of eating indoors or outdoors. Our findings suggest an investment in facilities has the potential to attract higher participation in the breakfast program and to increase students' intake of fresh fruit.

Schools that offered more variety of fruits were more likely to have made improvements in customer service, nutrition education, student attitudes and the quality and appeal of the fruit offered. Quality concerns were prominent in discussions with students about the changes in foods offered. Students noticed both positive and negative changes in food and beverage temperatures, freshness, taste, portion size and preparation.

In addition to presentation, the position of fruit in the serving sequence might affect student selections. At one points of service. Data from the evalua- site, the fruit was not visible; it had to be requested. Fresh fruit was the first item offered in the serving sequence at only three of the 13 sites where these data were recorded.

Nutrition directors at schools where students chose more fresh and total fruit were more likely to describe inadequate storage space and facilities. (Perhaps having to expand offerings heightened their awareness of inadequate facilities.)

\section{Nutrition education, promotion}

Many schools increased nutrition education and promotion efforts among students as part of the California Fresh Start Program but lacked the staff time and resources to mount a sufficiently intensive effort. Of the nutrition directors surveyed, $96 \%$ reported that lack of opportunity (time allotted in students' school day or an appropriate school location) was a barrier to fully providing the nutrition education component of the program, $87 \%$ reported a lack of staff time as a reason, and $81 \%$ reported that lack of funding was a barrier (table 4).

Lack of nutrition education for students was the third most commonly cited barrier to successfully providing additional servings of fresh fruit. Although it was intended that the program include a nutrition education component, schools were provided with only 1 cent per meal served (i.e., $10 \%$ of the 10 cents provided) for all nonfood expenses related to the program, including nutrition education and promotion. Yet, in spite of the limited funding, over half (57\%) of the schools did report using some nutrition education or promotional materials.

TABLE 4. Barriers to providing California Fresh Start Program-related nutrition education and promotion, as reported by child nutrition directors $(n=53)$

\begin{tabular}{lc} 
Barrier & Directors reporting \\
\hline & $\%$ \\
Lack of opportunity, time or & 96 \\
forum & 87 \\
Not enough staff time & 81 \\
Inadequate funding & 66 \\
Lack of materials & 55 \\
Lack of school support & 46 \\
Lack of student interest & 44 \\
Lack of staff training &
\end{tabular}


Although slightly more than half of nutrition directors had implemented some form of staff training, $40 \%$ reported that staff needed more training in the areas of fruit and vegetable handling and management and nutrition education in order to more effectively market fruits and vegetables to students. Nutrition, Family and Consumer Science advisors are poised to provide this kind of education and training.

\section{Elephant in the room: Finances}

The 10 cents per meal the program provided was substantially less than the amount required to cover a supplementary serving of fruit. Without considering the labor and other costs associated with serving additional fruit, the cost of the fruit alone was 3 cents higher than the 10 cent reimbursement, 4 cents above the 9 cents designated for food cost. The cost per serving for apples, oranges and bananas is 12 to 15 cents, whereas the other fruits offered in the program range from 14 to 25 cents per serving (table 5).

The 1 cent intended for all other costs, including labor, education and administrative expenses, was totally inadequate; labor costs for school food service departments usually account for $30 \%$ to $50 \%$ of expenses, and costs associated with storage and produce loss from perishability add to the expense of handling fresh produce. If the California Fresh Start Program were to offer a greater variety of fruits and higher-quality fruit, as students would prefer, fruit consumption would likely increase, leading to substantial increases in labor costs and costs of facility modification, as well as produce costs.

Most nutrition directors ( $81 \%$ ) reported that the program reimbursement was inadequate to cover the cost of implementing the program. Most schools either absorbed or could not quantify their nonfood expenses. Those that did report nonfood expenses spent an average of $\$ 2,784$, primarily on small equipment and educational materials.

Nutrition directors identified cost as the main barrier to providing a greater variety of fruits. They tended to serve fruit whole to reduce waste, increase shelf life and reduce labor costs associated with chopping fruit. They served apples, bananas and oranges most frequently because they are the most affordable. Student favorites such as strawberries
TABLE 5. Cost per serving of fresh fruits offered at school breakfast before and during the California Fresh Start Program ( $n=61$ schools*)

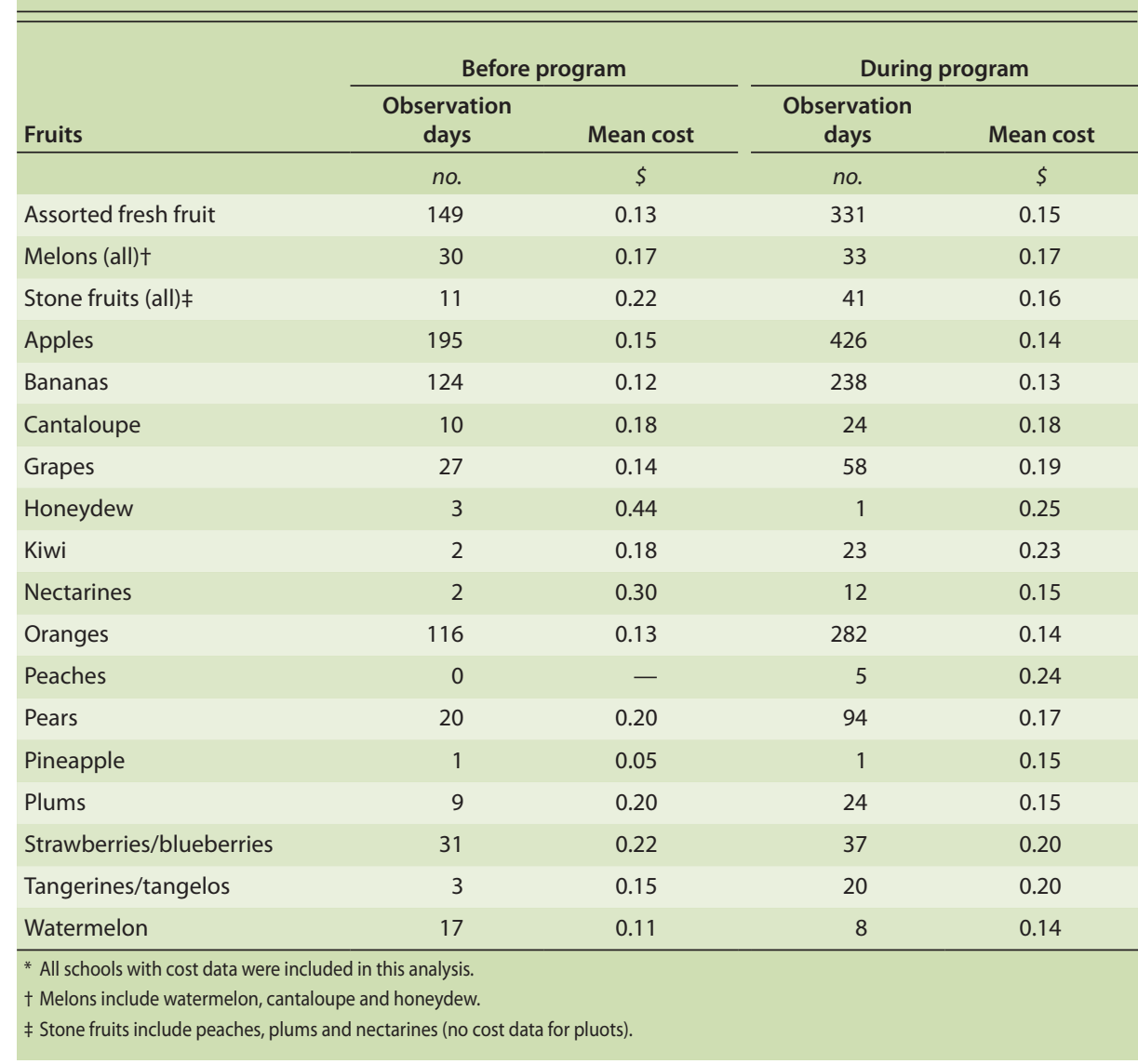

cost much more (table 5). To keep costs down, nutrition directors obtain their fruit whenever possible through the commodity food and Department of Defense programs. According to the nutrition directors, they could serve a greater variety of produce if these programs offered a more consistent supply and greater variety of fruits and vegetables.

Despite the perceived inadequacy of the reimbursement, many ( $45 \%$ ) nutrition directors thought the program was helpful financially and made it easier for them to provide more fruits because enrollment in the breakfast program increased. Higher participation rates in school breakfast might help to improve the bottom line by bringing in more federal reimbursement dollars. Participation increased slightly during the program, but the increase was too low to be statistically significant; it is not clear what would have happened over a longer period of time.

\section{Purchase of California fruit}

During the program, more Californiagrown fruit was sold and distributed
TABLE 6. Estimated percentage of the Fresh Start program fruit that was grown in California

Fruits Grown in California

\begin{tabular}{ll}
\hline & $\%$ \\
Grapes & 97 \\
Oranges & 95 \\
Strawberries/blueberries & 95 \\
Tangerines/tangelos & 95 \\
Stone fruits & 75 \\
Kiwi & 53 \\
Pears & 45 \\
Apples & 35 \\
Bananas & 0 \\
\hline
\end{tabular}

because the quantities of fruit and varieties of fruit purchased by schools increased. Using production records from schools participating in the program evaluation and interviews with selected produce distributors, we were able to estimate the proportion of produce the schools purchased that was California grown (see table 6). 
If all schools in California were to increase fresh produce offerings at breakfast, annual school purchases of California-grown fruit would increase by an estimated 26 million servings, valued currently at approximately $\$ 4$ million per year. These estimates are based on an average increase of at least one-third of a serving of fresh fruit per school breakfast meal served, an assumption that $47 \%$ of the fresh fruit served would be California grown, and an average cost per serving of 15 cents. Given this scenario, an additional $\$ 8.3$ million would be spent on fresh produce, of which approximately $\$ 3.9$ million would be spent on Californiagrown produce and $\$ 4.4$ million would be spent on fresh produce from other sources. If students' favorite fruits, which are primarily California grown, were served more often, our findings suggest students would take even more fruit at breakfast and therefore the increase in the value of school purchases of Californiagrown produce would be even higher.

According to school nutrition directors, produce vendors were a program asset, making it possible to increase fresh

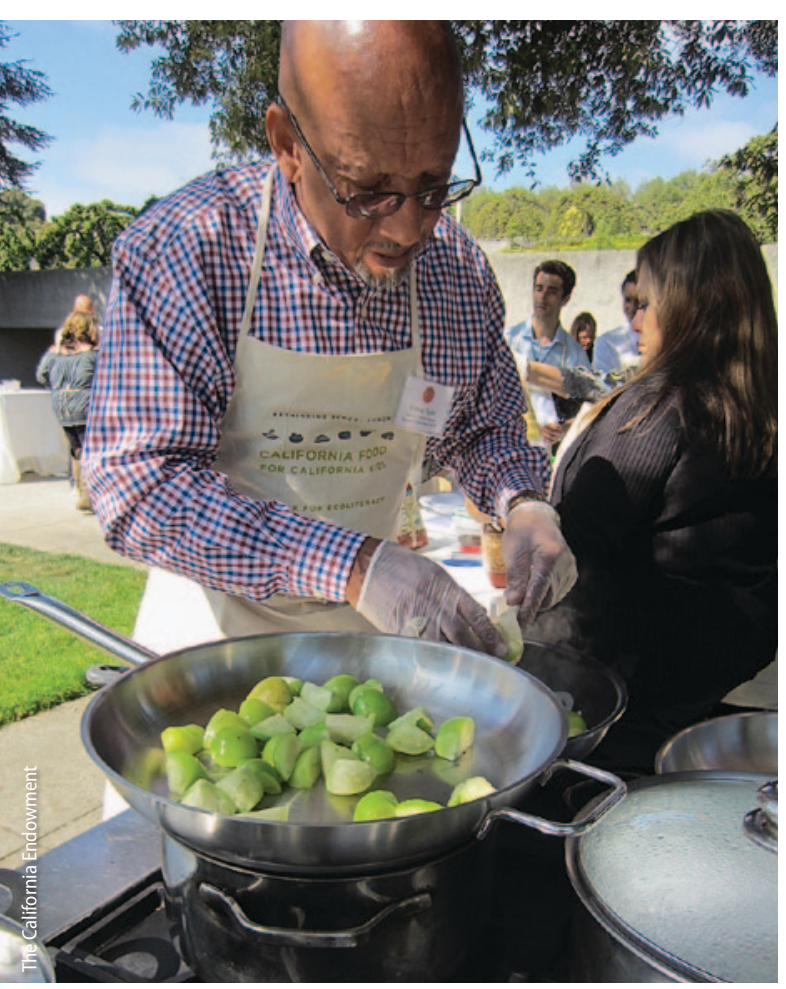

Using fresh tomatillos in a new recipe for California schools, Rodney Taylor, director of nutrition services at Riverside Unified School District, gave school leaders from across the state a taste test. Purchases of California-grown produce could rise significantly as schools expand their offerings of fruits and vegetables. fruit servings by providing dependable service, high quality and reasonable prices, and providing access to locally grown produce. While nutrition directors were enthusiastic about using more locally grown produce, some felt that they needed a go-between to procure the produce from local growers. Some reported that there were few, if any, local growers, and even if there were multiple local growers, it would be difficult to work directly with them. Directors expressed concern about supply, distribution, dependability, food safety and cost issues when dealing directly with local growers. Produce vendors were seen as necessary intermediaries between the schools and the growers as some directors felt that food service departments are not equipped to deal with many small growers. They preferred to continue dealing with the major suppliers with whom they have ongoing relationships.

Increased purchase of Californiagrown produce can be a win-win for schools, students, distributors and farmers. Food distributors (vendors) indicate that they prefer to purchase fresh fruit from California farmers, when available, as it is more affordable than fruit imported from out of state. Schools benefit from these savings, and farmers benefit from an increased market demand. The ultimate beneficiary is the student, whose increased consumption of fruit will contribute to long-term health.

\section{Lessons for future programs}

While the California Fresh Start Program was designed to provide more fruits and vegetables to students, its application to the breakfast program led to an overwhelming emphasis on fruit, and it is therefore impossible to draw conclusions about its potential impact on vegetable consumption from our data. However, other studies have indicated that increasing student vegetable consumption at other times in the school day presents greater challenges than are found with fruit (Hoffman et al. 2010; Ohri-Vachaspati et al. 2012). A systematic review of 27 school-based programs (26,361 students) designed to increase fruit and vegetable intake found that although the programs moderately improved fruit intake, they had minimal impact on vegetable consumption. The authors called for additional studies to address barriers to

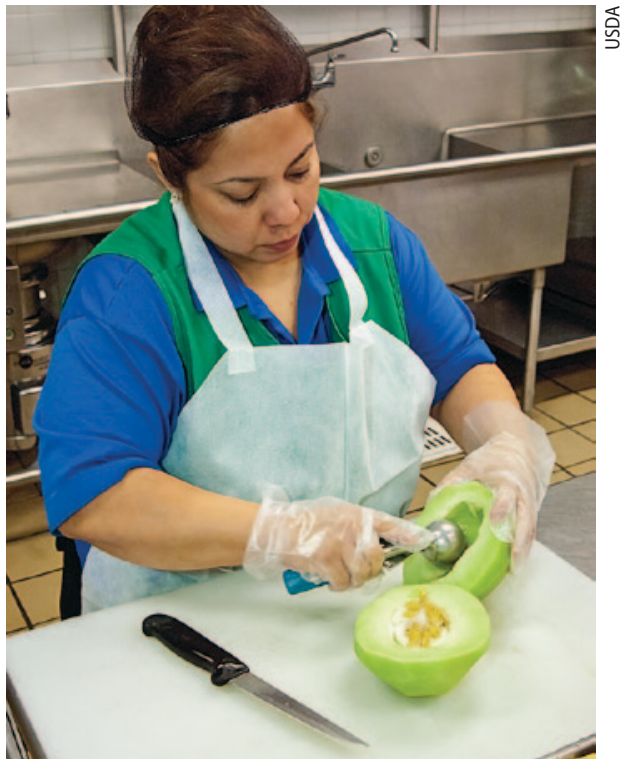

If melon and students' other favorite fruits were served more frequently, consumption would increase but so would costs. Above, an employee of Arlington Food Services prepares cantaloupe for students at Washington-Lee High School in Virginia.

changing dietary behavior, particularly in relation to vegetables (Evans et al. 2012).

As implemented, the California program was effective in increasing the amount of fruit, particularly the amount of fresh fruit, offered to and taken by California school children each day. Further, the variety of fruits offered, especially those that were fresh, increased substantially. The success of the program demonstrated that schools can have a positive impact on students' consumption of fruit, which is particularly important since produce consumption at school is lower than at home.

Piloting the program also provided lessons for the future implementation and expansion of such a program. Given the well-documented health risks that poor nutrition poses for California's school children and, at the same time, the likelihood that a school fruit program may decrease children's intake of unhealthy snacks at school (Overby et al. 2012), it is critical to closely examine those lessons.

The significant increase in the number of fruit servings students took at breakfast during the program was observed even in the absence of adequate funding to promote the effort or to upgrade facilities and equipment so that the fruit could be served in a way that would make it more attractive to students. Infusing additional resources for training, technical support 
and facilities upgrades, including, for example, improvements in storage capacity, adequacy and attractiveness of cafeteria seating, and creative presentation such as the use of salad-type fruit bars and pointof-service displays, could lead to even more substantial increases in the servings students take.

The program also was successful at shifting student consumption away from fruit juice toward fresh fruit. When schools serve less juice at breakfast, students take more fresh produce. Fruits are a healthier option than juice because of their higher levels of fiber and associated micronutrients. While the program resulted in a doubling of fruits offered to students at breakfast and a doubling of fresh fruit taken, a limitation of the study is the lack of assessment of the amount of fruit consumed. While not assessed in this study, improved variety and appeal in produce offerings, improved facilities, and more nutrition education could all potentially result in higher total consumption as well.

Our evaluation of the program suggested that school food service personnel faced a dilemma: If they took steps to improve the variety, presentation and promotion of fruit, their labor and food costs would increase beyond the 10 cents per meal provided by the program. At the same time, more students would likely take more fruit servings, particularly servings of fresh fruit, thereby further straining food service budgets. Our study suggests that additional financial resources will be required to ensure that most or all students take the recommended two servings of fruits and vegetables at breakfast.

If the program reimbursement were increased to 15 cents to better cover estimated actual costs (fruit cost of 13 cents plus 2 cents for labor, transportation and related nonfood costs) and if all eligible schools participated, the total reimbursement figure would be about \$26 million per year. School programs would further benefit from additional funding to make food service facilities adequate to store, prepare and serve fruits and vegetables in a safe and appealing manner. Interestingly, the USDA's Food and Nutrition Service recently estimated that the final meal pattern ruling mandating increases in whole grain and fruits in the School Breakfast Program would necessarily increase the cost of food and labor by 14 cents, an amount similar to our estimate for fruit (FNS 2012).

As part of the Healthy, Hunger-Free Kids Act of 2010, an extra 6 cents per meal in reimbursement was provided for school nutrition programs that complied with the mandate to increase the kinds and amounts of fruits and vegetables. As the final provisions of this act are implemented in schools across the nation, it will be important to evaluate school programs.

California has recognized the need to reverse the trend toward poor youth diets and has acknowledged the responsibility of schools to promote health. Unfortunately, lack of financial resources led the state to discontinue funding for the California Fresh Start Program after the pilot. However, new programs can benefit from lessons learned from the California program. There are currently changes taking place in school nutrition policy at the federal level. Partnerships among influential organizations and sectors, including growers, schools, public health agencies and others have been suggested as a lynchpin of the National Action Plan of the National Fruit and Vegetable Alliance (Thomson and Ravia 2011). The health of future generations depends upon our commitment to ensuring that everything possible is done to help today's youth adopt healthy food habits.

P.B. Crawford is Director, Atkins Center for Weight and Health, and Nutrition Specialist, Department of Nutrition Science and Toxicology, UC Berkeley; G. Woodward-Lopez is Associate Director, W. Gosliner is Director of Policy and K. Webb is Research Associate, Atkins Center for Weight and Health, UC Berkeley.

Funding for this research was provided by California Healthy Kids Resource Center and the Nutrition Services Division of the California Department of Education. The authors would like to thank the administrators, food service personnel and students of the participating schools for their involvement as well as Sheila Stern and Lauren Goldstein for their editorial assistance.

\section{References}

Blanchette L, Brug J. 2005. Determinants of fruit and vegetable consumption among 6- to 12-yearold children and effective interventions to increase consumption. J Hum Nutr Diet 18(6):431-43.

Briefel RR, Wilson A, Gleason PM. 2009. Consumption of low-nutrient, energy-dense foods and beverages at school, home, and other locations among school lunch participants and nonparticipants. J Am Diet Assoc 109:S79-590

[CDC] Centers for Disease Control and Prevention. 2011. Fruit and vegetable consumption among high school students-United States, 2010. MMWR Morb Mortal Wkly Rep 60(46):1583-6.

Coyle K, Potter S, Schneider D, et al. 2009. Distributing Free Fresh Fruit and Vegetables at School: Results of a Pilot Outcome Evaluation. Public Health Rep 124:660-9.

Delgado-Noguera M, Tort S, Martinez-Zapata MJ, et al. 2011. Primary school interventions to promote fruit and vegetable consumption: A systematic review and metaanalysis. Prev Med 53(1-2):3-9.

Evans CE, Christian MS, Cleghorn CL, et al. 2012 Systematic review and meta-analysis of school-based interventions to improve daily fruit and vegetable intake in children aged 5 to 12. Am J Clin Nutr 96:889-901.
[FNS] Food and Nutrition Service, USDA. 2010. Fresh Fruit and Vegetable Program: A Handbook for Schools. www. fns.usda.gov/cnd/ffvp/handbook.pdf (accessed June 19, 2012).

FNS. 2012. Nutrition Standards in the National School Lunch and School Breakfast Programs. Final rule. Fed Regist. 77(17):4088-167.

Glickman D, Parker L, Sim L, et al. (eds). 2012. Accelerating Progress in Obesity Prevention: Solving the Weight of the Nation. Washington DC: National Academies Press. Guenther P, Dodd K, Reedy J, et al. 2006. Most Americans eat much less than recommended amounts of fruits and vegetables. J Am Diet Assoc 106(9):1371-9.

He M, Beynon C, Sangster Bouck M, et al. 2009. Impact evaluation of the Northern Fruit and Vegetable Pilot Programme-a cluster randomised controlled trial. Public Health Nutr 12(11):2199-208.

Hoffman JA, Franko DL, Thompson DR, et al. 2010. Longitudinal behavioral effects of a school-based fruit and vegetable promotion program. J Pediat Psychol 35(1):61-71.
Kimmons J, Gillespie C, Seymour J, et al. 2009. Fruit and vegetable intake among adolescents and adults in the United States: Percentage meeting individualized recommendations. Medscape J Med 11(1):26.

Knai C, Pomerleau J, Lock K, et al. 2006. Getting children to eat more fruit and vegetables: A systematic review. Prev Med 42(2):85-95.

Ohri-Vachaspati, Turner L, Chaloupka FJ. 2012. Fresh fruit and vegetable program participation in elementary schools in the United States and availability of fruits and vegetables in school lunch meals. J Acad Nutr Diet 112(6):921-6.

Overby NC, Klepp KI, Bere E. 2012. Introduction of a school fruit program is associated with reduced frequency of consumption of unhealthy snacks. Am J Clin Nutr 96(5):1100-110

Thomson CA, Ravia J. 2011. A systematic review of behavioral interventions to promote intake of fruit and vegetables. J Am Diet Assoc 111(10):1523-35.

[USDA DHHS] US Department of Agriculture and US Department of Health and Human Services. 2010. Dietary Guidelines for Americans, 2010. Washington, DC: US Government Printing Office. 